\title{
GÊNEROS E FORMAÇÃO: REPRESENTAÇÕES DE PROFESSORES EM
} RELATOS DE EXPERIÊNCIA

\author{
Claudia Lopes PONTARA \\ (SEED/PPGEL/UEL) \\ lpontara@bol.com.br \\ Marileuza Ascencio MIQUELANTE \\ (UNESPAR) \\ mikelante@gmail.com \\ Vera Lucia Lopes CRISTOVÃO \\ (UEL/CNPq) \\ veraluciacristovao@gmail.com
}

\begin{abstract}
Resumo: Neste trabalho relatamos e discutimos como se deu o processo de produção coletiva de material didático de Língua Inglesa para o Centro de Línguas Estrangeiras Modernas do Estado do Paraná - CELEM. Tal produção foi feita por professores da rede estadual de educação, sob a orientação de professores de duas universidades brasileiras. Para tanto, partindo dos pressupostos teóricos sobre aprendizagem no viés vigotskiano e gêneros na perspectiva do Interacionismo Sociodiscursivo, os relatos de experiência dos professores participantes desse processo são analisados em relação: a) ao contexto; b) ao plano textual global; c) à identificação de segmentos de orientação temática (BRONCKART, 2008); e d) à discussão de um dos segmentos identificados. Nosso objetivo é discutir representações construídas pelos professores participantes em relação ao Segmento de Orientação Temática (SOT) aprendizagem (conhecimento prévio e conhecimento adquirido). Assim, este estudo se justifica ao possibilitar o (re)pensar e/ou (re)discutir a formação continuada de professores, com base em gêneros, evidenciando a dimensão da aprendizagem.
\end{abstract}

Palavras-chave: Gêneros Textuais. Aprendizagem. Formação Continuada.

Abstract: This paper aims at reporting and discussing the process of collective production of didactic material for the teaching of English at the Center of Modern Foreign Languages of the State of Paraná - CELEM, by teachers of the Public Sector, under the supervision of professors from two Brazilian Universities. Moreover, based on the theoretical construct of learning in the vigotskian sense and genre in the sociodiscursive perspective, experience reports written by participant teachers are analysed regarding: a) context; b) global textual plan; c) identification of theme-oriented segments (TOS). (BRONCKART, 2008). Our objective is to discuss the representations built by participant teachers concerning learning (previous knowledge and acquired knowledge.) Thus, this study is justified so as to provide (re)thinking and/or 
(re)discussing teacher education on a genre-based perspective, emphasizing the learning dimension.

Keywords: Textual Genre. Learning. Continuing Education.

\section{Notas Introdutórias}

Trazemos para este artigo representações construídas sobre a experiência vivida por alguns professores de língua inglesa do Estado do Paraná, os quais se dispuseram a fazer parte de um grupo de produtores de material didático a ser utilizado nas turmas de língua inglesa do Centro de Línguas Estrangeiras Modernas do Estado do Paraná - CELEM. Para tanto, foi solicitado a todos os participantes que redigissem um relato de experiência enfocando aprendizagem. Buscamos discutir representações construídas pelos professores participantes em relação à aprendizagem - conhecimento prévio e conhecimento adquirido.

Partindo dos pressupostos teóricos sobre aprendizagem no viés vigotskiano e gêneros na perspectiva do Interacionismo Sociodiscursivo, os relatos de experiência dos professores participantes desse processo, são analisados em relação a) ao contexto; b) ao plano textual global; c) à identificação de segmentos de orientação temática - SOT (BRONCKART, 2008); e d) à discussão do SOT aprendizagem. Assim, este estudo se justifica ao possibilitar o (re)pensar e (re)discutir a formação continuada de professores, com base em gêneros, evidenciando a dimensão da aprendizagem.

O artigo segue a seguinte organização: na seção 1, trazemos uma breve fundamentação teórica sobre aprendizagem no viés vigotskiano e sobre o Interacionismo Sociodiscursivo (doravante ISD). Na seção 2, apresentamos o percurso metodológico. A seção 3 destina-se à apresentação e discussão dos resultados. E, finalmente, a seção 5 traz algumas notas (in)conclusivas. 


\section{Fundamentação Teórica}

1.1 Aprendizagem e desenvolvimento em Vigotski e o papel dos instrumentos de mediação

Pensarmos o papel da formação continuada como fator de contribuição para aquele que atua no processo de ensino e aprendizagem de língua inglesa (LI) sob a perspectiva da abordagem de gêneros à luz do ISD, nos remete aos pressupostos teóricos da Psicologia Histórico-Cultural, a qual concebe 0 homem como um ser sócio-historicamente constituído.

Vigotski $^{1}$ (2009) postula alguns conceitos imprescindíveis para o seu trabalho com vistas à compreensão do processo de desenvolvimento. Os principais conceitos tratados são: interação, mediação e internalização.

Assim, Vigotski (op.cit) defende que, para o indivíduo melhorar o seu nível de aprendizagem, é necessário mais do que apenas agir, é preciso interagir, ou seja, para o autor todo sujeito adquire seus conhecimentos a partir das relações interpessoais com o meio. Desta forma, o que inicialmente parece ser um resultado individual é, na verdade, coletivo. Nesse processo de construção coletiva, por meio da língua, da linguagem e dos símbolos escolhidos para as trocas, o sujeito se constrói, internaliza o conhecimento, se transforma e transforma o meio em que se insere.

No que se refere à mediação, segundo Oliveira (2002, p.26), para Vigotski este é, em termos genéricos, "o processo de intervenção de um elemento intermediário numa relação; a relação deixa, então, de ser direta e passa a ser mediada por esse elemento." Diante disso, questionamos: o que vem a ser o elemento intermediário no processo de mediação? De acordo com Richit (2004), para falarmos em mediação precisamos explicitar aspectos inerentes aos elementos mediadores, classificados como: instrumentos, signos e sistemas simbólicos.

\footnotetext{
${ }^{1}$ Sempre que fizermos referência a esse autor utilizaremos a grafia conforme citado na obra, em outros momentos, manteremos a grafia como a que aqui se encontra por ser esta a da obra de referência para nós.
} 
Vygotski (1991) aponta o instrumento, juntamente com o trabalho, como elementos essenciais para que o homem transforme a natureza e, assim, transforme-se a si mesmo. Esse autor argumenta que 0 instrumento pode servir como um fio condutor entre o homem e o objeto a fim de possibilitar-lhe que atinja um determinado objetivo, servindo-Ihe como mediador na relação do sujeito com o mundo. O signo passa a ocupar a função de mediador, sendo um recurso utilizado pelo sujeito para controlar ou orientar sua conduta no processo de interação com o mundo, agindo no sentido de ativar outra atividade psicológica, memória, por exemplo, pois representa ou expressa objetos, fatos.

De acordo com Vygotski (1991), à medida que ocorre a internalização dos signos, surgem os sistemas simbólicos que são estruturas de signos articuladas entre si. O uso de sistemas simbólicos, como a linguagem, por exemplo, favorece o desenvolvimento social, cultural e intelectual dos grupos culturais e sociais ao longo da história.

Em suma, podemos dizer que a mediação ocorre quando em uma relação há o uso de instrumentos e atividades socialmente organizadas, sejam eles instrumentos simbólicos materiais ou humanos. A mediação ocorrida por meio da linguagem, das relações sociais e da mediação simbólica pode propiciar ao indivíduo a aprendizagem do conhecimento, dos papeis sociais e valores que fazem parte da cultura.

Dos conceitos de Vigotski (2009), temos ainda a internalização que, segundo ele, acontece no momento em que a aprendizagem se constrói, consistindo no resultado de uma série de eventos ocorridos ao longo do desenvolvimento humano. Nesse sentido, Fittipaldi (2006, p. 52) esclarece que no processo de internalização

[...] não há um antes e um depois; um dentro/fora, como é comum se pensar, o que na verdade ocorre é um movimento dialético, em que há a negociação entre os sentidos privados (hipóteses que o sujeito traz consigo) e o significado público ou social (representações dos tempos, papéis e práticas sociais), sendo que o que é apropriado, [...] é de natureza semiótica: a significação da ação e não a ação em si mesma. Desse modo, ao internalizar, o sujeito modifica sua percepção das coisas, sua capacidade de solucionar problemas, ou seja, suas Funções Psicológicas Superiores. 
Enfim, corroboramos com a perspectiva vigotskiana no que tange à aprendizagem e ao desenvolvimento, não como processos únicos ou independentes, mas aquela como fonte geradora deste e, pautadas por esse entendimento, passamos a tratar dos construtos teóricos do ISD.

\subsection{O Interacionismo Sociodiscursivo e seus aportes teórico-metodológicos}

Neste tópico, abordaremos os posicionamentos dos autores da Escola de Genebra, aos quais nos filiamos pela proposta da linha teórico-metodológica do ISD, cujos conceitos vêm sendo formulados há aproximadamente duas décadas, por Bronckart e outros colaboradores, postulando que os processos de construção social e cultural do sujeito são indissociáveis do processo de desenvolvimento humano.

O quadro teórico-metodológico do ISD parte das concepções de Hegel, Marx e Engels, Spinosa, Simmel e Schütz, Giddens, Bakhtin, Mead (18631931) e Vigotski (1896-1934). Há, portanto, nessa perspectiva, uma reunião de diversas correntes das ciências humanas. Por essa razão, o ISD é definido por Bronckart (2007) como uma ciência do humano, a qual se apoia em teorias de linguagem que consideram 0 aspecto social como sendo fulcral ao desenvolvimento humano, fundamentando-se na teoria psicológica de Vygotsky (1993).

Assim, para a perspectiva teórico-metodológica aqui adotada, as atividades e as produções de linguagem do ambiente social são de extrema importância, pois são elas que conduzem o desenvolvimento humano na direção de um pensamento consciente. É, portanto, no quadro das atividades sociais de linguagem e no quadro da formação social, que as ações de linguagem dos indivíduos se desenvolvem pela materialização nos textos.

Em relação à ação de linguagem, Bronckart (2007, p.99) defende que esta pode ser definida em dois níveis. No

(...) primeiro nível, sociológico, como uma porção da atividade de linguagem do grupo, recortada pelo mecanismo geral das avaliações sociais e imputada a um organismo humano singular (...) e [num] segundo nível, psicológico, como o conhecimento, disponível em um organismo ativo sobre as diferentes facetas de sua própria responsabilidade na intervenção verbal. 
Com isso, tomando esses dois níveis como aspectos fundamentais à constituição do ser humano em seu desenvolvimento social, ressaltamos a importância da utilização das formas comunicativas de uma determinada formação social, convertida em gênero de texto. O desenvolvimento da humanidade é permeado por diferentes atividades sociais, para as quais, geralmente, utilizamos uma variedade de textos a fim de suprir as necessidades de comunicação. "Nessa perspectiva, os gêneros de textos são produtos de configurações de escolhas entre esses possíveis, que se encontram momentaneamente "cristalizados" ou estabilizados pelo uso." (BRONCKART, 2006, p. 143)

Partindo dos pressupostos teórico-metodológicos norteadores do ISD, Dolz, Noverraz e Schneuwly (2004) propõem como dispositivo didático a sequência didática - SD, um procedimento para o desenvolvimento de atividades pedagógicas organizadas, de maneira sistemática, contendo um número preciso de objetivos, com vistas a ajudar o estudante a dominar diversos gêneros de textos que permeiam nossa vida em sociedade, prepará-lo para saber usar a língua nas mais variadas situações sociais, bem como oferecer-lhe instrumentos eficazes para melhorar suas capacidades de linguagem, sejam elas orais ou escritas.

Os autores em questão agrupam os gêneros a serem trabalhados na escola, considerando um certo número de regularidades linguísticas, bem como algumas ações linguísticas da ordem do narrar, relatar, argumentar, expor e descrever ações. Dessa forma, a estrutura de base de uma SD é constituída pelos seguintes passos: "apresentação da situação, produção inicial, módulo 1, módulo 2, módulo n e produção final".

Nesse sentido, vinculamos a aprendizagem vigotskiana aos pressupostos do ISD ressaltando que a linguagem é considerada como um fenômeno social e histórico, como uma "produção interativa associada às atividades sociais, sendo ela o instrumento pelo qual os interactantes, intencionalmente, emitem pretensões à validade relativas às propriedades do meio em que essa atividade se desenvolve" (BRONCKART, 2007, p.34). 
A seguir, trataremos dos procedimentos metodológicos para 0 desenvolvimento da pesquisa.

\section{Metodologia da pesquisa}

Para a realização de nossa pesquisa adotamos o viés qualitativo, o qual possibilita a compreensão e a explicação do processo de interação entre os sujeitos, considerando "o universo de significados, motivos, aspirações, crenças, valores e atitudes, o que corresponde a um espaço mais profundo das relações sociais, dos processos e dos fenômenos que não podem ser reduzidos à operacionalização de variáveis" (MINAYO, 1999, p. 21-22).

No ano de 2010, todos os professores de Língua Estrangeira (Inglês, Francês e Espanhol) ${ }^{2}$ da Rede Estadual receberam um convite da Coordenação Geral do CELEM/SEED ${ }^{3}$ para se candidatarem a um processo de escolha de professores que constituiriam o grupo de elaboradores do Material Didático para esse contexto. Como critério de seleção, foi analisada uma Unidade Didática com base em um gênero textual, produzida pelo próprio professor. Entre os inscritos, dez professores foram selecionados para compor o grupo de Língua Inglesa, os quais estiveram sob a orientação de professoras oriundas de duas diferentes universidades brasileiras. O processo de produção das unidades que comporiam o material ocorreu durante os anos de 2010, 2011 e 2012, conforme o quadro abaixo:

\footnotetext{
2 Embora o CELEM oferte o ensino de 09 idiomas, o material didático foi elaborado apenas para as três línguas mencionadas, por serem essas as línguas com maior número de turmas e alunos em todo o Paraná.

${ }^{3}$ Secretaria de Estado da Educação do Paraná.
} 


\section{Ação}

\begin{tabular}{|c|c|}
\hline $\begin{array}{c}\text { Período de } \\
\text { realização }\end{array}$ & $\begin{array}{c}\text { Número de } \\
\text { participantes }\end{array}$ \\
\hline 2009 & - \\
\hline $\begin{array}{r}23 / 02 \text { a } 30 / 03 / \\
2010\end{array}$ & 11 professores \\
\hline $01 / 03 / 2010$ & \\
\hline 17 a 20/05/2010 & 10 professores \\
\hline 04 a $08 / 07 / 2011$ & 09 professores \\
\hline 26 a $30 / 09 / 2011$ & 07 professores \\
\hline 07 a $11 / 05 / 2012$ & 06 professores \\
\hline
\end{tabular}

Quadro 1: Fases da elaboração do material didático

A geração de dados para este artigo aconteceu no primeiro semestre de 2013, por meio da solicitação de um Relato de Experiência proposto por uma das integrantes da produção coletiva do material, a qual, no momento, está cursando o mestrado com o foco na reconfiguração do trabalho do professor em sala de aula, durante a implementação de uma das sequências didáticas produzidas coletivamente. Tal solicitação foi enviada a todos os dez (10) professores selecionados. Desses, cinco (05) concluintes do processo -

\footnotetext{
${ }^{4}$ Coordenação de Formação Continuada.
} 
chamados aqui de P1, P2, ... - enviaram seus relatos. Apenas um dos concluintes não atendeu a solicitação.

O quadro a seguir apresenta dados relevantes sobre a vida profissional desses participantes da pesquisa.

\begin{tabular}{|l|l|l|}
\hline \multicolumn{1}{|c|}{ Formação } & \multicolumn{1}{|c|}{ Tempo de Serviço } & \multicolumn{1}{c|}{ Local de origem } \\
\hline P1 - mestrado e PDE & Mais de 30 anos & Curitiba - capital do estado \\
P2 - especialização e PDE & Entre 20 e 30 anos & Apucarana - centro-norte \\
P3 - mestrado e PDE & Entre 20 e 30 anos & Campo Mourão - centro-oeste \\
P4 - mestrado e PDE & Entre 10 e 20 anos & Curitiba - capital do estado \\
P5 - especialização & Entre 10 e 20 anos & Matinhos - litoral \\
\hline
\end{tabular}

Quadro 2: Dados de identificação profissional dos participantes

De posse dos relatos, realizamos a análise dos mesmos a partir dos seguintes procedimentos:

- Análise contextual subjacente à produção do material didático;

- Reconhecimento do plano textual global dos relatos de experiência;

- Identificação dos SOT por meio da análise do desenvolvimento do conteúdo temático;

- Discussão de excertos do SOT aprendizagem.

A seguir passamos à discussão dos resultados obtidos.

\section{Resultado e discussão dos dados}

3.1 Análise contextual: o CELEM e a formação continuada por meio da produção coletiva de material didático

As escolas públicas do Estado do Paraná ofertam, por meio do CELEM, cursos de Línguas Estrangeiras para alunos, professores e funcionários da rede estadual, bem como para a comunidade. E tal qual ocorre com a Língua Estrangeira na Matriz Curricular, as Propostas Pedagógicas dos Cursos do

\footnotetext{
${ }^{5}$ Programa de Desenvolvimento Educacional.
} 
CELEM são elaboradas a partir dos referenciais teórico-metodológicos contidos nas Diretrizes Curriculares Estaduais de Língua Estrangeira Moderna DCE/LEM (2008), as quais trazem como prioridade o trabalho com gêneros, concebendo a língua como discurso.

Muito embora as DCE já tenham chegado às mãos dos professores, em sua versão definitiva, desde o ano de 2008, é possível verificar que o trabalho com gêneros ainda não se efetiva completamente nas aulas de LEM da Matriz Curricular e até mesmo do CELEM, devido a vários fatores, entre eles, a inexistência de um material didático sob esta perspectiva.

No caso específico do CELEM, esse fato se torna ainda mais grave, uma vez que tais cursos não possuem material didático específico, e nem mesmo recebem o Livro Didático Público do Programa PNLD, ficando a critério de cada professor a organização de seus próprios materiais, o que se torna quase impossível, diante das condições objetivas do fazer docente, tais como: sobrecarga de trabalho, infraestrutura precária, problemas na formação inicial e continuada, entre outros. Além disso, há também o agravante de as DCE não deixarem claro ao professor como ele poderia implementar tal proposta teóricometodológica.

Tais considerações nos levam a crer que, mesmo tendo as diretrizes norteadoras para o ensino de LEM, enfatizando o trabalho com gêneros textuais, ainda continuamos com grande parte das aulas sendo ministradas com o foco na gramática e tradução e/ou na abordagem comunicativa - fato esse que se comprova quando analisamos alguns documentos elaborados por professores, tais como: Plano de Trabalho Docente e Livro Registro de Classe ${ }^{6}$.

Frente a esse cenário que se apresenta, a Coordenação Geral do CELEM assumiu uma postura pró-ativa ao propor a produção de um material didático específico para esse contexto.

\footnotetext{
${ }^{6} \mathrm{~A}$ análise desses documentos foi feita por duas das autoras, no ano de 2012, período em que exerciam a função de técnicas pedagógicas responsáveis pelo CELEM nos NRE.
} 
3.2 Reconhecimento do plano textual global e segmentos de orientação temática: a voz dos professores participantes nos relatos de experiência

A análise do plano textual global dos relatos mostrou-nos o quão intenso foi o processo vivenciado pelos cinco professores que se dispuseram a colaborar com essa pesquisa. Esses professores, chamadas de P1, P2, P3, P4 e P5 produziram seus textos, abordando vários outros SOT, além daquele elencado para análise neste trabalho. Na sequência apresentamos a síntese de cada relato, incluindo os SOT identificados.

$P 1$, em um texto de 808 palavras, enfatiza os ganhos profissionais que obteve, bem como seu interesse pela busca de novos conhecimentos, uma vez que os seus eram diferentes das teorias norteadoras da produção coletiva do material, apontando para a necessidade de estudo, leitura e compreensão de conceitos relacionados aos gêneros textuais e a sua didatização. Ao final, esclarece que ao longo do processo o seu entendimento sobre tais conceitos foi se solidificando.

P2, em 1150 palavras, deixa claro que o interesse em participar do grupo veio em decorrência de sua necessidade de aprender mais sobre as teorias ensino por meio de gêneros textuais e sequência didática - em razão de suas atribuições enquanto técnica pedagógica do NRE, sendo uma dessas, a de atuar como formadora dos professores de LEM. Enfatiza o seu pouco conhecimento sobre os aspectos teóricos já mencionados, muito embora tivesse participado de todas as formações ofertadas pelo CELEM. Seu relato marca os conflitos vivenciados, mas também, e principalmente, os avanços obtidos quanto a sua aprendizagem, a qual se deu por meio das interações ocorridas no grupo.

O relato de $\mathrm{P} 3$, organizado em 766 palavras, traz, assim como os demais, uma breve menção acerca de seus conhecimentos prévios, deixando muito marcada a sua concepção de formação continuada ao mencionar que a produção do material era vista como um processo, o que constitui, verdadeiramente, a formação continuada. Seu texto também mostra o interesse em conhecer mais sobre a teoria do ISD e da sequência didática. Assim como os outros professores, $\mathrm{P} 3$ enfatiza em vários momentos o seu desenvolvimento teórico-metodológico, mediado pelas trocas e interações. 
$\mathrm{P} 4$, ao tratar do processo de produção coletiva de material como uma iniciativa ousada e pioneira, destaca, em seu texto de 584 palavras, a importância da valorização dos saberes construídos coletivamente pelos próprios atores da escola pública (os professores). Menciona, também, os conflitos do trabalho coletivo advindos, em parte, das concepções trazidas por cada uma das participantes. O relato também apresenta o movimento do professor entre desconstrução e construção de conhecimento, voltados para concepções de língua, linguagem e gêneros.

P5 traz para seu relato, de 1102 palavras, pontos que não foram abordados, ou ainda, que foram abordados de forma menos destacada pelos demais professores. O professor assinala a falta de condições materiais, estruturais, tais como: a não dedicação exclusiva para realizar o trabalho proposto, a falta de esclarecimento sobre questões que envolvem a produção de material didático (diagramação, direitos autorais, por exemplo). Assinala também as deficiências que enxerga em sua formação continuada, mas não deixa de enfatizar seu avanço em termos de formação profissional.

Após análise do plano textual global de cada relato, identificamos os SOT e fizemos um recorte de modo a possibilitar as discussões relacionadas à aprendizagem - conhecimento prévio e conhecimento adquirido.

3.3 SOT aprendizagem: dos conhecimentos prévios aos conhecimentos adquiridos

Uma das hipóteses que levantamos ao iniciar este artigo é a de que a proposta de trabalho organizada pela Coordenação Geral do CELEM tinha como fim a produção de um material didático, e o meio para se atingir esse fim seria proporcionar encontros com professoras consultoras/orientadoras que fariam as orientações para tal atividade. Contudo, para os professores participantes, a produção coletiva do material propiciou a apropriação de novos conhecimentos, em vários aspectos, conforme excertos abaixo: 


\begin{tabular}{|c|c|c|}
\hline & onhecimentos prévios & Conhecimentos adquiridos (aprendizagem) \\
\hline P1 & $\begin{array}{l}\text { "Já havia lido algumas coisas sobre } \\
\text { ensino de línguas a partir do trabalho com } \\
\text { gêneros textuais, mas de forma rápida e } \\
\text { solitária, sem ter muitas pessoas com } \\
\text { quem pudesse discutir essa proposição } \\
\text { mais a fundo." } \\
\text { "Confesso que minha expectativa sobre a } \\
\text { conceituação de discurso estava pautada } \\
\text { no que tinha ouvido sobre o discurso em } \\
\text { Foucault." }\end{array}$ & $\begin{array}{l}\text { "[...] foi de muita leitura, discussões e aprendizagem } \\
\text { em conjunto com as demais participantes do grupo de } \\
\text { produção de material da língua inglesa." } \\
\text { "À medida que desenvolvíamos o trabalho, pude ir } \\
\text { entendendo um pouco mais a teoria de Gêneros a } \\
\text { partir de Bronckart, e a didatização de gêneros } \\
\text { proposta por Schnewly (sic) e Dolz para o ensino e } \\
\text { aprendizagem de línguas na escola." }\end{array}$ \\
\hline כל & $\begin{array}{l}\text { "[...] embora eu já tivesse participado do } \\
\text { PDE e também [...] de algumas formações } \\
\text { ofertadas pelo próprio CELEM, sentia que } \\
\text { havia muita coisa sobre o ensino por meio } \\
\text { de gêneros, sobre a Sequência Didática } \\
\text { que eu não conhecia ou somente tinha } \\
\text { ouvido falar, de forma superficial." } \\
\text { "Assim que cada professor foi falando um } \\
\text { pouquinho sobre a unidade que havia } \\
\text { preparado, fomos nos dando conta de que } \\
\text { as diferenças eram muito grandes entre os } \\
\text { materiais produzidos." } \\
\text { "Como éramos um grupo formado por } \\
\text { professores de diferentes contextos, cada } \\
\text { um de nós trazia as suas crenças e } \\
\text { concepções teórico-metodológicas e } \\
\text { administrar isso não foi nada fácil." }\end{array}$ & $\begin{array}{l}\text { "E hoje, quando olho para essa primeira produção, é } \\
\text { que posso avaliar o quanto eu cresci, o quanto adquiri } \\
\text { conhecimento. E isso não foi somente em relação às } \\
\text { teorias (gêneros, ISD, SD), mas também em relação à } \\
\text { própria língua, ao uso dos recursos tecnológicos." } \\
\text { "[...] ao mesmo tempo que fazíamos as leituras } \\
\text { indicadas [...] tínhamos que ir produzindo o nosso } \\
\text { material. Foi a teoria sendo internalizada ao mesmo } \\
\text { tempo em que a colocávamos em prática, na situação } \\
\text { de elaboradores de material didático." } \\
\text { "As mediações feitas pela professora orientadora foram } \\
\text { super importantes [...], pois íamos percebendo, a cada } \\
\text { conversa, que o caminho podia ser trilhado de forma } \\
\text { diferente. [...] E isso com certeza contribuiu para nosso } \\
\text { crescimento e aprendizagem." } \\
\text { "O meu pouco conhecimento sobre o ensino por meio } \\
\text { de gêneros já tinha sido expandido [...]" }\end{array}$ \\
\hline P3 & $\begin{array}{l}\text { "[...] a orientadora das produções seria a } \\
{[\ldots] \text { autora que só conhecia por meio dos }} \\
\text { textos que havia lido. Vale mencionar que } \\
\text { os tais textos despertavam meu interesse } \\
{[\ldots] . "} \\
\text { "[...] Passei alguns dias revendo uma } \\
\text { unidade que havia preparado e aplicado } \\
\text { no período do meu mestrado norteado } \\
\text { pela Pedagogia Crítica (2000-2002)." }\end{array}$ & $\begin{array}{l}\text { "Tivemos uma semana de trabalho intenso. Quanto } \\
\text { pensamos, quanto discutimos, quanto aprendemos." } \\
\text { "A cada encontro que acontecia, mais inquietações, } \\
\text { mais trabalho, novas orientações e novos } \\
\text { conhecimentos sendo construídos." } \\
\text { "[...] posso dizer que participar da produção [...] me } \\
\text { proporcionou desenvolvimento teórico-metológico[...]" }\end{array}$ \\
\hline P4 & $\begin{array}{l}\text { "[...] necessidade de desconstrução de } \\
\text { nossas concepções de ensino de LEM, } \\
\text { resultado de históricos de experiências } \\
\text { heterogêneas, formação acadêmica, } \\
\text { práticas pedagógicas na área de LEM, } \\
\text { atuação e desenvolvimento da carreira } \\
\text { profissional, ao longo do tempo." }\end{array}$ & $\begin{array}{l}\text { "O desafio para a reconstrução e construção de novos } \\
\text { conhecimentos para o desenvolvimento do trabalho no } \\
\text { grupo, foi da mesma forma intensa e positivamente } \\
\text { marcada pela necessidade de aquisição de } \\
\text { conhecimentos em áreas afins [...]" }\end{array}$ \\
\hline P5 & $\begin{array}{l}\text { "[...] as concepções que foram colocadas } \\
\text { se afastaram muito do que tínhamos } \\
\text { produzido. Pessoas de localidades muito } \\
\text { diferentes, com práticas muito distintas } \\
{[\ldots] \text { "... }}\end{array}$ & $\begin{array}{l}\text { "[...] agradeço a evolução profissional que adquiri } \\
\text { através dele. Algo que, provavelmente, não teria } \\
\text { acontecido se não tivesse me disposto a participar." } \\
\text { "Hoje vejo o quanto às poucas coisas produzidas } \\
\text { anteriormente por mim eram primárias [...]" }\end{array}$ \\
\hline
\end{tabular}

Quadro 3: Excertos dos relatos dos professores participantes 
Ao analisarmos os excertos referentes ao conhecimento prévio percebemos que há uma heterogeneidade nos conhecimentos trazidos pelos participantes da produção coletiva do material didático. No entanto, P1, P2 e P3 evidenciam algum tipo de conhecimento acerca do ensino por meio de gêneros e da sequência didática (DOLZ, NOVERRAZ E SCHNEUWLY, 2004), demonstrando que o grupo necessitava de uma mediação feita por um par mais experiente, ora a professora consultora/orientadora ora os próprios participantes do processo executavam tal função.

Conforme defendido por Schneuwly (2004), uma vez transformado o instrumento, a atividade pode ser transformada. Nesse sentido, os excertos evidenciam a transformação tanto do que os professores participantes acreditavam caracterizar um material (instrumento) quanto da atividade de planejar e produzir coletivamente esse material (instrumento). A produção coletiva de material representa essa atividade que necessita de mediação ao mesmo tempo em que se volta para a criação de um instrumento. Essa mediação ora era marcada por instrumentos simbólicos materiais (textos para leitura conforme citados por P1 e P2) ora por instrumentos humanos (citado por $\mathrm{P} 2$ ), ou seja, o movimento existente no processo possibilitou e contribuiu para a aprendizagem das envolvidas (VIGOTSKI, 2009).

Quanto ao conhecimento adquirido (aprendizagem), notamos que os cinco informantes da pesquisa indicam algum tipo de avanço em relação ao conhecimento prévio, o qual se deu em função da interação e da mediação realizada pela professora orientadora e pelos pares mais experientes, conforme postulado por Vigotski (2009). Tal prática indica que o movimento de participação oscila entre a periférica e a central, em função dos conhecimentos de cada uma das envolvidas no processo (WENGER, 1991).

Além dos excertos anteriores, há outro fragmento extraído do texto de P5 que corrobora o dito:

Pude perceber por comentários de colegas presentes durante o processo, que muitas práticas e ideias a respeito já estavam muito além das nossas crenças e postura. Que apesar de fazermos parte do mesmo órgão empregador, eles haviam tido acesso diferente ao nosso, a falas e capacitações a este respeito. Senti-me, de certa forma, privilegiada, por ter visto e ouvido novas concepções, novas alternativas, novas ferramentas de ensino. Ter discutido e refletido sobre elas. 
Tanto esse trecho como os demais indicam que todos consideram ter havido um aprimoramento - pessoal ou profissional - ao longo do processo, ou seja, que não apenas foram produtores de material, mas que puderam aprender e/ou ensinar e refletir sobre os conhecimentos que já traziam consigo, bem como sobre os adquiridos em relação ao gênero de texto e à sequência didática, considerados por nós como relevantes para a atividade realizada pelo grupo (VYGOTSKI, 1991).

\section{Notas (in)conclusivas}

A análise feita a partir dos relatos redigidos pelos professores demonstrou com muita clareza que uma proposta de trabalho não planejada como formação continuada, assumiu tal papel por ter sido significativa e produtiva, sendo capaz de envolver os professores em atividades concretas, desafiadoras, reflexivas, voltadas para a concretização de um objetivo comum.

É importante ressaltar que o exemplo de trabalho norteado pela perspectiva vigotskiana à luz do ISD, apresentado neste artigo, deu-se a partir de uma proposta de produção de material didático. Contudo, cremos que qualquer outro propósito de trabalho pode vir a ser executado sob tal perspectiva, desde que tal proposta venha ao encontro das necessidades e interesses dos professores envolvidos, para que então haja, efetivamente, o engajamento a ponto de se estabelecer fortes vínculos e comprometimentos em prol de um mesmo objetivo.

Nesse sentido, é possível dizer que ao desenvolver um trabalho que considera o conhecimento prévio dos participantes para, a partir dele, (re)configurar novas práticas e se estabelecer uma relação de diálogo honesto (condição primordial para esse tipo de trabalho), divergências terão que ser negociadas, implicando no estabelecimento de confiança, segurança e respeito, os quais são condições essenciais para que ocorra a aprendizagem.

A nosso ver, a atividade de produção coletiva de material possibilitou oportunidades de aprendizagem, conforme evidenciado pelos excertos dos relatos de experiência. Tais oportunidades serviram-se de elementos do agir constituídos por dimensões coletivas e individuais. Essas dimensões reúnem elementos da ordem de motivos, engajamento, recursos e capacidades para agir. 


\section{Referências bibliográficas}

BRONCKART, J.P. Atividade de Linguagem, textos e discursos: por um Interacionismo sóciodiscursivo; trad. Anna Rachel Machado, Péricles Cunha 2.ed., 1. Reimpr. - São Paulo: Educ, 2009.

O agir nos discursos: das concepções teóricas às concepções dos trabalhadores. Trad. Ana Raquel Machado, Maria de Lourdes Meirelles Matêncio. Campinas, SP: Mercado de Letras, 2008.

Atividade de Linguagem, discurso e desenvolvimento humano./Jean-Paul Bronckart; organização Anna Rachel Machado e Maria de Lourdes Meirelles Matencio; tradução Anna Rachel Machado e Maria de Lourdes Meirelles Matencio [et. al.] - Campinas, SP: Mercado de Letras, 2006. - (série Ideias sobre Linguagem).

DOLZ, J.; NOVERRAZ, M. \& SCHNEUWLY, B. Sequências Didáticas para o oral e a escrita: apresentação de um procedimento. In: Gêneros orais e escritos na escola. Trad. e Org. Roxane Rojo e Glaís Sales Cordeiro. Campinas: Mercado de Letras, 2004.

FITTIPALDI, B. Conceitos Centrais de Vygotsky: implicações pedagógicas. Revista Educação - UNG, vol. 1, oํ 2. 2006 . Disponível em < http://revistas.ung.br/index.php/educacao/article/viewArticle/33> acesso em 09 de setembro de 2013.

LAVE, J.; WENGER, E. Situated Learning: legitimate peripheral participation. Cambridge University Press, 1991.

MINAYO, M.C.S. Pesquisa Social: Teoria, Método e Criatividade. 14a Ed. Petrópolis, RJ: Vozes, 1999.

OLIVEIRA, M.K. Vygotsky: aprendizado e desenvolvimento, um processo sócio-histórico. 4. ed. São Paulo: Scipione, 2002.

PARANÁ, Secretaria de Estado da Educação. Diretrizes Curriculares da Educação Básica Língua Estrangeira Moderna, Curitiba, 2008.

RICHIT, A. Implicações da Teoria de Vygotsky aos Processos de Aprendizagem e Desenvolvimento em Ambientes Mediados pelo Computador. 103 - Ciências Exatas e da Terra. V.28 - Setembro/2004. Disponível em http://www.uricer.edu.br/new/rperspectiva/inicio.php?id numero=21 acesso em 07/09/2013. 
VIGOTSKI, L.S. A construção do pensamento e da linguagem. Trad. Paulo Bezerra. $2^{a}$ ed. São Paulo: Martins Fontes, 2009.

VYGOTSKY, L.S. Pensamento e Linguagem. Trad. Jeferson Luiz Camargo. São Paulo: Martins Fontes, 1993.

VYGOTSKI. L.S. A formação social da mente. Trad. José Cipolla Neto, Luiz Silveira Menna Barreto, Solange Castro Afeche. São Paulo: Martins Fontes, 1991. 
Artigo recebido em: 20/12/2013

Artigo avaliado em: 23/06/2014

\section{Sobre as autoras:}

Mestre em Estudos da Linguagem pela Universidade Estadual de Londrina UEL.

Mestre em Linguística Aplicada na área de Ensino-Aprendizagem de Segunda Língua e Língua Estrangeira pela Universidade Estadual de Campinas.

Professora associada da Universidade Estadual de Londrina (UEL), membro do Programa de Pós Graduação em Estudos da Linguagem (PPGEL-UEL) e líder do grupo de pesquisa Linguagem e Educação. 